\title{
Surgical treatment of idiopathic mediastinal fibrosis: report of five cases
}

\author{
IM MITCHELL, NR SAUNDERS, O MAHER, SC LENNOX, DR WALKER \\ From the Departments of Cardiothoracic Surgery, Killingbeck Hospital, Leeds, and Brompton Hospital, London
}

ABSTRACT Idiopathic mediastinal fibrosis is a rare disease of unknown aetiology. It is a benign condition in which abnormal proliferation of fibrous tissue occurs within the mediastinum, leading to constriction and obliteration of local structures, particularly the great veins. It is a rare cause of superior vena caval obstruction (1-2\%) but one that is potentially amenable to surgical palliation. The results of venous reconstruction in five patients with superior vena caval obstruction secondary to idiopathic mediastinal fibrosis are reported. Reversed autogenous saphenous vein grafts were used in two patients, woven silicone rubber prostheses in two, and bovine pericardial conduits in one patient. Useful long term results were obtained in three patients, but the bovine pericardial graft and one of the vein grafts failed within a few weeks.

Idiothaphic mediastinal fibrosis is a benign condition first described in 1757 by John Hunter. ${ }^{1}$ It is characterised by abnormal proliferation of fibrous tissue within the mediastinum, and may be regarded as one of a group of similar fibrosclerotic conditions, which include retroperitoneal fibrosis, pseudotumour of the orbit, Reidel's thyroiditis, Dupuytren's contracture, and Peyronie's disease. The histological similarity between mediastinal fibrosis and retroperitoneal fibrosis in particular, and the observation that they often coexist in the same patient, has led to the belief that they may represent the same pathological process.

The aetiology of idiopathic mediastinal fibrosis is obscure, but various factors have been implicated, in particular infection with tuberculosis and histoplasmosis, the drug methysergide, and autoimmune processes. ${ }^{2}$ The disease occurs equally in males and females and predominantly affects people in the second to the fifth decades. Mediastinal fibrosis may constrict or obliterate any structure located in the mediastinum, but because of their thin walls and low intraluminal pressures venous structures (superior vena cava and pulmonary veins) tend to be compressed earlier than the arteries and the tracheobronchial tree. For this reason superior vena caval obstruction and haemoptysis are the most common symptoms of the disease.

Address for reprint requests: Mr NR Saunders FRCS, Killingbeck Hospital, Leeds LS14 6UQ.

Accepted 24 July 1985
The condition is rarely life threatening, but the quality of life in these patients is poor. The results of conservative treatment have been disappointing, but with the development of materials specifically designed as venous grafts, ${ }^{34}$ and the improved patency rates now reported with autogenous vein and other graft materials, ${ }^{5}$ the clinician should reconsider the role of surgery in the treatment of superior vena caval obstruction due to idiopathic mediastinal fibrosis. We report on the results of venous reconstruction in five such patients.

\section{Clinical details}

Five patients were studied, three men and two women, aged 30-48 years old. The clinical history was similar in all cases, with seven months' to three years' duration of swelling of the face and upper extremities. On examination all had obvious features of superior vena caval obstruction, with no lymphadenopathy, and clear lung fields on the chest radiograph. Only one patient had any evidence of retroperitoneal fibrosis and none had evidence of any other associated fibrosclerotic conditions. The results of tests for histoplasmosis were negative, but all patients showed a positive reaction to tuberculin testing. Cytological examination of sputum and bronchoscopy were unhelpful in establishing a histological diagnosis. A superior venacavogram obtained by combined synchronous injection of contrast into both subclavian veins showed in each case the site and extent of the obstruction and the degree of collateral circulation 


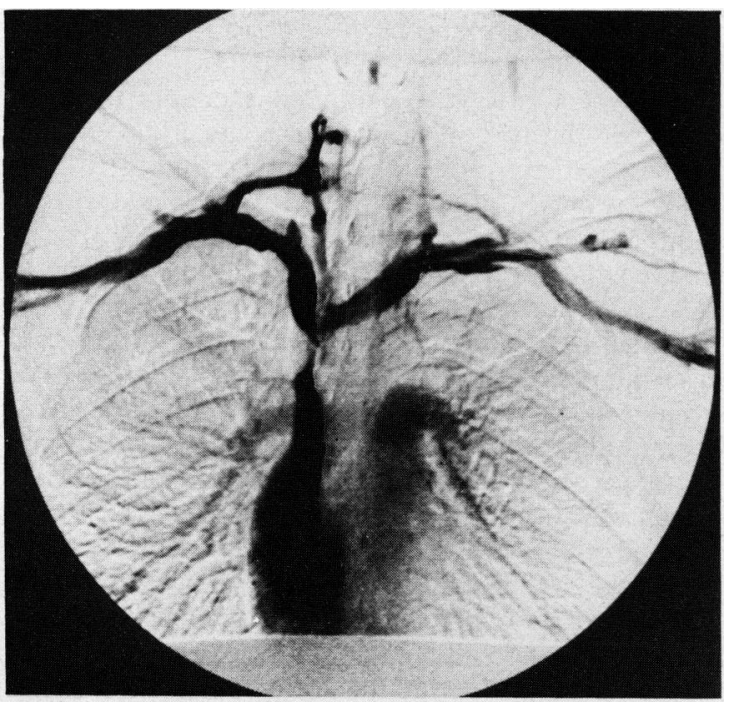

Fig 1 Patient 2: Superior venacavogram showing the typical appearances of idiopathic mediastinal fibrosis.

(fig 1).

Each operation was performed by the same surgeon (DRW) via a median sternotomy. The advantage of this is that it can be extended into the neck for exposure and control of both subclavian and internal jugular veins. The dilated collateral circulation was preserved so far as possible, but nevertheless resulted in heavy blood loss.
In each case a hard fibrous mass was found in the mediastinum, infiltrating and occluding the superior vena cava at the junction of the right and left brachiocephalic veins. The right phrenic nerve was always entrapped in the mass but was freed, with difficulty, in each case. In only two patients could the mass be excised completely. In other cases local infiltration into surrounding tissue prevented excision.

Three types of graft material were used: reversed autogenous saphenous vein grafts (two patients), woven silicone rubber prostheses (two patients), and glutaraldehyde fixed bovine pericardial grafts (one patient).

\section{Results}

In all five patients there was a dramatic relief of symptoms immediately after operation, but in two patients (one with a vein graft and one with a bovine pericardial graft) symptoms returned within a few weeks as a result of graft failure (table). The first of the two patients subsequently had antituberculous treatment, penicillamine, anticoagulants, and steroids; with this regimen 16 months after operation her symptoms, although still present, have once again improved. After graft failure in the second patient the symptoms of superior vena caval obstruction returned and persisted; renal failure developed as a result of inferior vena caval obstruction caused by retroperitoneal fibrosis. He died 16 months after operation from bleeding oesophageal varices.

Details of surgical treatment and progress in the five patients

\begin{tabular}{|c|c|c|c|c|c|c|}
\hline \multicolumn{3}{|c|}{ Patient } & \multirow{2}{*}{$\begin{array}{l}\text { Date of } \\
\text { operation }\end{array}$} & \multirow[t]{2}{*}{ Graft material } & \multirow[t]{2}{*}{ Treatment } & \multirow[t]{2}{*}{ Progress } \\
\hline No & Sex & Age (y) & & & & \\
\hline $1^{*}$ & $\mathbf{M}$ & 48 & May 1973 & $\begin{array}{l}\text { Autogenous saphenous } \\
\text { vein }\end{array}$ & $\begin{array}{l}\text { Double vein bypass graft from } \\
\text { left brachiocephalic vein to } \\
\text { SVC }\end{array}$ & $\begin{array}{l}\text { Relief of symptoms; no } \\
\text { obstruction on venacavogram } \\
\text { at } 13 \mathrm{~m} \text { (follow up } 11 \text { years) }\end{array}$ \\
\hline 2 & $\mathrm{~F}$ & 33 & Sept 1983 & $\begin{array}{l}\text { Autogenous saphenous } \\
\text { vein }\end{array}$ & $\begin{array}{l}\text { Saphenous vein bypass grafts } \\
\text { from left and right } \\
\text { brachiocephalic veins to } \\
\text { SVC }\end{array}$ & $\begin{array}{l}\text { Relief of symptoms for } 2 \mathrm{w} \text {, then } \\
\text { grafts clotted (confirmed on } \\
\text { venacavogram at } 7 \mathrm{~m} \text { ); } \\
\text { symptoms returned but have } \\
\text { since improved with medical } \\
\text { treatment (follow up } 2 \mathrm{y} \text { ) }\end{array}$ \\
\hline $3^{*}$ & $\mathbf{M}$ & 36 & June 1974 & $\begin{array}{l}\text { Woven silicone rubber } \\
\text { prosthesis }\end{array}$ & $\begin{array}{l}\text { Y graft from right and left } \\
\text { brachiocephalic veins } \\
\text { to proximal SVC }\end{array}$ & $\begin{array}{l}\text { Relief of symptoms; no } \\
\text { obstruction on venacavogram } \\
\text { at } 9 \mathrm{~m} \text { (follow up } 10 \mathrm{y} \text { ) }\end{array}$ \\
\hline $4^{*}$ & $\mathrm{~F}$ & 35 & Aug 1973 & $\begin{array}{l}\text { Woven silicone rubber } \\
\text { prosthesis }\end{array}$ & $\begin{array}{l}\text { Mass excised; grafts from } \\
\text { right and left } \\
\text { brachiocephalic veins to } \\
\text { SVC and right atrium (fig 2) }\end{array}$ & $\begin{array}{l}\text { Relief of symptoms; no } \\
\text { obstruction on venacavogram } \\
\text { at } 6 \mathrm{~m} \text { (follow up } 11 \mathrm{y} \text { ) }\end{array}$ \\
\hline 5 & $\mathbf{M}$ & 30 & April 1982 & Bovine pericardial graft & $\begin{array}{l}\text { Mass excised; single branched } \\
\text { graft from right and left } \\
\text { brachiocephalic and left } \\
\text { internal jugular veins to } \\
\text { right atrium (fig 3) }\end{array}$ & $\begin{array}{l}\text { Initial complete relief of } \\
\text { symptoms; deterioration at } \\
3 \mathrm{w}-\text { venacavogram showed } \\
\text { blockage of left } \\
\text { brachiocephalic limb and } \\
\text { stenosis at anastomotic lines; } \\
\text { later developed renal failure } \\
\text { due to retroperitoneal fibrosis } \\
\text { and died } 16 \mathrm{~m} \text { after operation. }\end{array}$ \\
\hline
\end{tabular}




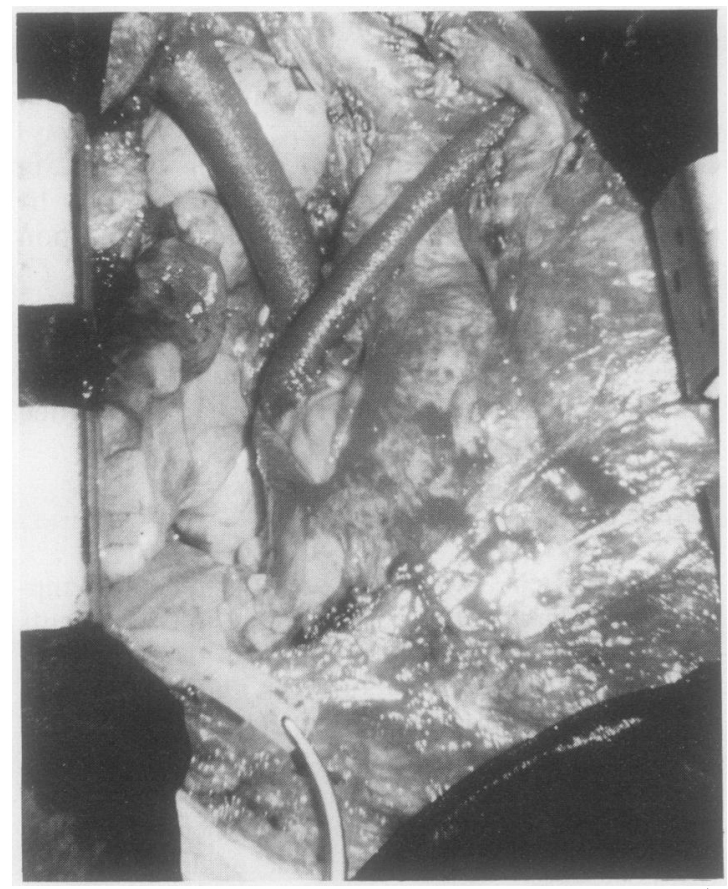

Fig 2 Patient 4: Woven silicone rubber grafts from the right and left brachiocephalic veins to the proximal superior vena cava and right atrium.

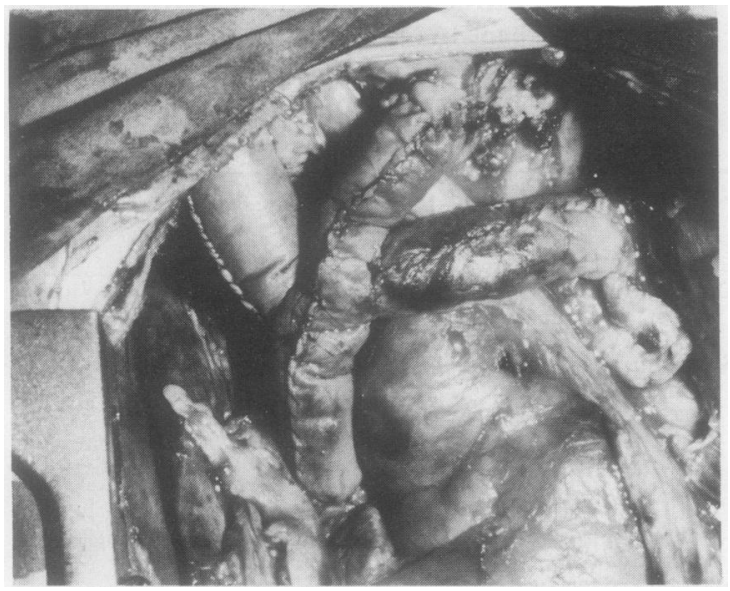

Fig 3 Patient 5: Single branched pericardial graft from the right and left brachiocephalic and left internal jugular veins to the right atrium.

The three patients with a successful outcome all report relief of symptoms during the 10 or 11 years of follow up.

\section{Discussion}

Superior vena caval obstruction is usually due to malignant disease and in most cases radiotherapy is the treatment of choice. Idiopathic mediastinal fibrosis is a rare condition and accounts for only $1-2 \%$ of all cases of superior vena caval obstruction; in these patients radiotherapy is contraindicated ${ }^{16}$ as it may promote a further fibrotic reaction and worsen venous obstruction. ${ }^{7}$ Since, however, the results of venous reconstructive procedures in this condition have been poor, ${ }^{6-10}$ many physicians have elected to manage these patients conservatively, with diuretics, anticoagulants, steroids, and penicillamine. The results of a conservative approach to idiopathic mediastinal fibrosis have also been disappointing. In one series of eight patients, four had venous reconstructive procedures and were symptom free one, 10 , 11 , and 12 years after operation, whereas none of the conservatively managed patients showed relief of symptoms and two showed considerable deterioration. ${ }^{11}$ Despite the clinical relief of symptoms in the operated group the venous graft remained patent in only one of the four patients. The clinical relief of symptoms therefore may not necessarily be correlated with graft patency. ${ }^{12}$ To a certain extent the disease is self limiting and there will be progressive relief of symptoms as the collateral circulation develops, but without treatment the patient will never become symptom free. ${ }^{1}$

In our series, three out of five patients have had long term relief of symptoms after venous grafting, and neither of the two patients whose grafts failed has developed worse symptoms than were present before operation. These results favour a surgical rather than a conservative approach, ${ }^{11}$ both because this allows histological proof of the diagnosis and because it may also produce a dramatic relief of symptoms.

Although in comparison with arterial grafts the results of venous reconstructive procedures have been generally poor, ${ }^{11}$ the superior vena cava does seem to be a privileged site in the venous system, as both synthetic and biological grafts show a much greater patency rate here than elsewhere. ${ }^{13}$ This may be due to negative intrathoracic pressure and the effect of $\rightarrow$ gravity, which provides a greater intraluminal flow in the superior vena cava than elsewhere in the venous $\tilde{N}$ system.

Materials that have been used for venous grafts $N$ include synthetic fabrics such as Dacron, Gortex, and $\underset{\omega}{N}$ woven silicone rubber, and biological materials such 2 as autogenous vein, aortic homografts, bovine peri- $Q$ cardium, and small bowel. So far the best results of $\mathbb{D}$ reconstruction of the superior vena cava have been $\stackrel{\mathcal{P}}{+}$ achieved with autogenous vein. ${ }^{11}$

It has been observed that vein grafts are more likely to remain patent if they are the same diameter as the $\stackrel{\mathcal{P}}{\mathcal{P}}$ venous channels to which they are anastomosed. ${ }^{11} \mathbb{Q}$ For this reason Chiu et $a l^{14}$ described a technique for 
creating large diameter grafts from small veins: if the side branches on a piece of saphenous vein of small diameter are tied off, this can be cut longitudinally, wound up, and sutured into a spiral of any size. Use of the spiral vein graft has been reported successfully on several occasions, most recently by Doty in $1982::^{15}$ all 10 of his patients had patent superior vena caval bypass grafts at 18 months. In our series one of the two vein grafts remained patent.

Autogenous vein grafts are susceptible to obliteration by whatever pathological process has caused obliteration of the original venous channels. Thus where the fibrotic tissue of idiopathic mediastinal fibrosis cannot be completely excised stented synthetic grafts may be of more value. Only autogenous vein grafts, however, have been found to recanalise after thrombosis. ${ }^{16}$

The use of woven silicone rubber as a venous prosthesis was first reported in 1969. ${ }^{17}$ This material is inert and promotes minimal tissue reaction; the grafts are therefore less likely to become obstructed by a surrounding fibrotic process. Most grafts that fail within the first week do so as a result of primary thrombosis, whereas late occlusion (one to five weeks after operation) usually occurs secondary to the formation of scar tissue at the anastomotic lines. ${ }^{11}$

It has been shown that late occlusion of grafts rarely occurs if a neointima forms early, ${ }^{12}$ and woven silicone rubber has the advantage that it allows tissue ingrowth with rapid endothelialisation of the graft. Woven silicone rubber grafts are easy to handle and pliable and they hold sutures well, ensuring good anastomosis. The results are satisfactory in both patients in this series after 10 years' follow up.

The third type of venous prosthesis used in this series was constructed of bovine pericardium. The advantage of this material is that it is readily available and can be used for the construction of grafts of any size. Several studies, however, have shown that pericardial grafts have a high thrombogenic potential. ${ }^{18-20}$ The mesothelial lined surface is composed of dense connective tissue, which is resistant to tissue ingrowth. Early formation of thrombus at suture lines commonly occurs, with inevitable complete occlusion of the graft at a later stage. ${ }^{18}$ In addition, pericardial tube grafts lack sufficient strength to prevent compression by external fibrosis. ${ }^{20}$

Attempts to increase patency by creating an arteriovenous fistula between graft and internal mammary artery have met with some success. ${ }^{12}$ In contrast to the arterial circulation, where turbulence results in increased thrombus formation, ${ }^{21}$ in vein grafts turbulence may be beneficial. ${ }^{18}$ The increased intraluminal flow or pressure may contribute to improved patency initially. ${ }^{12}$ Most fistulas are likely, however, to close spontaneously and merely provide optimum conditions for rapid endothelialisation of the suture lines and graft lumen. ${ }^{18}$ Anticoagulants and antiplatelet drugs were not given at any stage in this series, although there is some evidence that they are of benefit in maintaining graft patency. ${ }^{1922}$

The goal for successful replacement of great veins in idiopathic mediastinal fibrosis is to find a graft that allows early endothelialisation, causes little tissue reaction, has minimal tendency to collapse or kink, and has properties that facilitate surgical techniques. There is some evidence that Gortex (polytetrafluoroethylene) may meet these demands, ${ }^{20}$ but the use of this material has not been evaluated in the long term. As the wealth of different materials available would suggest, there is at present no single material that is entirely satisfactory for use as a venous replacement graft in idiopathic mediastinal fibrosis.

\section{References}

1 Barrett NR. Idiopathic mediastinal fibrosis. Br J Surg 1958;46:207-18.

2 Light AM. Idiopathic fibrosis of mediastinum: a discussion of three cases and review of the literature. J Clin Pathol 1978;31:78-88.

3 Gott VL, Furuse A. Antithrombogenic surfaces: classification and in vivo evaluation. Fed Proc 1971; 30:1679-85.

4 Soyer T, Lempinen M, Cooper P, Norton L, Eiseman B. A new venous prosthesis. Surgery 1972;72:864-71.

5 Miller RE, Sullivan FJ. Superior vena caval obstruction secondary to fibrosing mediastinitis. Ann Thorac Surg 1973;15:483-92.

6 Hache L, Woolner LB, Bernatz PE. Idiopathic fibrous mediastinitis. Chest 1962;41:9-25.

7 Leszczynski St Z. Purulent and fibrous mediastinitis: radiological diagnosis. Warsaw: Polish Medical Publishers, 1972.

8 Cooley DA, Hallman GL. Superior vena caval syndrome treated by azygos vein-inferior vena cava anastomosis. J Thorac Cardiovasc Surg 1964;47:325-30.

9 Hanlon CR, Danis RK. Superior vena caval obstruction: indications for diagnostic thoracotomy. Ann Surg 1965;161:771-7.

10 Longmire WP, Goodwin WE, Buckberg GD. Management of sclerosing fibrosis of the mediastinal and retroperitoneal areas. Ann Surg 1967;165:1013-21.

11 Scherck JP, Kerstein MD, Stansel HC Jr. The current status of vena caval replacement. Surgery 1974; 76:209-33.

12 Hiratzka LF, Wright CB. Experimental and clinical results of grafts in the venous system: a current review. J Surg Res 1978;25:542-61.

13 Haimovici H, Hoffert PW, Zinicola N, Steinman C. An experimental and clinical evaluation of grafts in the venous system. Surg Gynecol Obstet 1970;131:1173-86.

14 Chiu CJ, Terzis J, Macrae ML. Replacement of superior vena cava with the spiral composite vein graft. Ann Thorac Surg 1974;17:555-60. 
15 Doty DB. Bypass of superior vena cava: six years' experience with spiral vein graft for obstruction of superior vena cava due to benign and malignant disease. J Thorac Cardiovasc Surg 1982;83:326-38.

16 Dale WA, Scott HW Jr. Grafts of the venous system. Surgery 1963;53:52-74.

17 Ashton F, Geddes R, Fejfar J. Woven silicone rubber as a venous prosthesis. $\mathrm{Br}$ Med J 1969;iii:409-10.

18 Miller RE, Corneil NJ, Sullivan FJ. Replacement of superior vena cava with autogenous tissue. Ann Thorac Surg 1973;15:474-82.

19 Brais M, Bertranou E, Brassard A, Stanley P, Char- trand C. Effect of dextran on patency of pericardial tubular graft of the superior vena cava in the dog. $J \overline{\bar{N}}$ Thorac Cardiovasc Surg 1973;65:296-303.

20 Fiore AC, Brown JW, Cromartie RS, et al. Prosthetic replacement for the thoracic vena cava. $J$ Thorac Cardiovasc Surg 1982;84:560-8.

21 Brais MP, Braunwald NS. Tissue acceptance of materials implanted within the circulatory system. Arch Surg $\frac{2}{0}$
1974;109:351-8.

22 Hasegawa T, Matsumoto $H$, Yamamoto M, Fuse K, $\vec{\circ}$ Mizuno A, Saigusa M. Prosthetic replacement of superior vena cava. Arch Surg 1973;106:848-50. 